\title{
TWO NEW SPECIES OF TEAGUEIA (ORCHIDACEAE: PLEUROTHALLIDINAE) FROM EAST-CENTRAL ECUADOR
}

\author{
LOU JOST ${ }^{1,3}$ \& ANDERSON SHEPARD ${ }^{2}$ \\ ${ }^{1}$ Via a Runtun, Baños, Tungurahua, Ecuador \\ 22307 N. Wallace Ave, Bozeman, MT 59715 USA \\ ${ }^{3}$ Author for correspondence: loujost@gmail.com
}

\begin{abstract}
Abstract: Two new species of Teagueia, T. barbeliana and T. puroana, are described and illustrated. Their relationship to other Teagueia, their scientific importance, and their conservation is discussed. Closest relatives are T. alyssana, T. sancheziae, T. cymbisepala, and T. jostii, and like them, the new species are highelevation $(>3100 \mathrm{~m})$ endemics of the upper Río Pastaza watershed in the eastern Andes of Ecuador. Teagueia barbeliana differs from its relatives by broad rounded flower parts, lateral sepals connate for half their length, column apex winged. Teagueia puroana differs from relatives by its long-acuminate petals and sepals.

Resumen. Se describen e ilustran dos nuevas especies del género Teagueia, T. barbeliana y T. puroana. Se discuten sus afinidades, su importancia para la ciencia, y su conservación. Las especies más cercanamente emparentadas con las nuevas son T. alyssana, T. sancheziae, T. cymbisepala, y $T$. jostii, que al igual que las nuevas, son endémicas a las alturas $(>3100 \mathrm{~m})$ de la cuenca alta del Río Pastaza en los Andes Orientales del Ecuador. Teagueia barbeliana se distingue por sus sépalos y pétalos redondos, sus sépalos laterales unidos hasta la mitad de su longitud, y las alas en el ápice de la columna. Teagueia puroana se distingue por sus pétalos y sépalos con colas largas..
\end{abstract}

KeY words: Teagueia puroana, Teagueia barbeliana, Ecuador, orchid, new species

Prior to the year 2000, Teagueia Luer was known from only three Colombian and three Ecuadorian species, each apparently endemic to very small areas (Luer 1991). In the year 2000, LJ discovered four new species of Teagueia in one square meter of moss at $3100 \mathrm{~m}$ on a remote mountain in the upper Río Pastaza watershed in the province of Tungurahua in Ecuador, on the rim of the Amazonian basin of South America. Those species were described as T. alyssana Luer \& L. Jost, $T$. sancheziae Luer \& L. Jost, $T$. cymbisepala Luer \& L. Jost, and T. jostii Luer (Luer 2000). Further investigation led to the discovery of many more new species on that same mountain and neighboring mountains, all in cloud forest or páramo (alpine grassland) above 2800m (Jost 2004). The total number of new high-elevation morphospecies now known from the upper Río Pastaza watershed is about 28 (including the four formally described species just mentioned, and the two new ones described here).

Characteristics of the new species and their relatives. All of the 28 locally endemic high-elevation morphospecies are slender, long-repent plants with loose, successive-flowering inflorescences. The longrepent habit easily distinguishes them from all other Teagueia species. The flowers also differ slightly from the previously-known Ecuadorian species of the genus. Teagueia zeus (Luer \& Hirtz) Luer, T. teagueii (Luer) Luer, and T. tentaculata Luer \& Hirtz all have a raised callus on the lip just below the column. In addition, the orifice in the center of their lip, which is characteristic of the genus, is long and narrow, extending almost from the callus to the apex of the lip. In the 28 long-repent species, on the other hand, there is no raised callus, and the orifice occupies less than half the midlobe of the lip.

Both of the new species described here are easily distinguished from all other described Teagueia species. Teagueia barbeliana is most like T. cymbisepala, but has more rounded flower parts than that species; the lateral sepals in particular are very broad and connate for half their length, each with four veins as opposed to the three or fewer veins of other known species. The lateral lobes of the lip clasp the column just behind the 
stigma. The three-veined petals and winged column tip are also unusual. Teagueia puroana is most like $T$. alyssana, but it is immediately distinguished by the long tails on all sepals and petals exclusive of the lip, combined with lateral sepals that are only connate for $1 / 5$ of their length, and lateral lobes of the lip which clasp the column just behind the stigma.

Evolution of the Teagueia species of the upper Río Pastaza watershed. The similarity of the 28 upper Río Pastaza watershed long-repent morphospecies of Teagueia strongly suggests that they form a monophyletic group. Preliminary results of molecular work on nearly all morphospecies by Mark Whitten, Kurt Neubig, and Lorena Endara (University of Florida- Gainesville), and previous unpublished work on a subset of species by Alec Pridgeon (Kew) and by Erik Rothacker (Ohio State University), confirm this. These morphospecies thus constitute one of the earth's most remarkable local plant evolutionary radiations, with more species in a much smaller area than better-known recently-evolved plant radiations such as Darwin's Scalesia Arn. (Asteraceae) on the Galapagos Islands (Tye 2000). The only comparable orchid radiation is the Dendrochilum Blume radiation on Mount Kinabalu, Borneo (Barkman \& Simpson 2001). Molecular work by Mark Whitten's group at UF Gainesville may soon be able to assign a time scale on this Teagueia radiation, which appears to be very young, like many other Andean plant radiations (Hughes \& Eastwood 2006, Scherson et al. 2008).

Distribution patterns of the Teagueia species in the upper Río Pastaza watershed. Almost all of these 28 Teagueia morphospecies appear to be restricted to a $30 \mathrm{~km}$ x $20 \mathrm{~km}$ block of forest bisected by the steep valley of the Río Pastaza, an important tributary of the Amazon. Extensive botanizing in the páramos and high cloud forests along the Quito-Baeza road and the páramos of Pisayambo (Parque Nacional Los Llanganates) north of the Río Pastaza failed to turn up any of these species. South of the Río Pastaza, we have found only two species on the GuamoteMacas road (70-90 km south of the Río Pastaza) and no species farther south. There are however many unexplored high mountains in the Llanganates range and between the Río Pastaza and the Guamote-Macas road, where additional as-yet-unknown species may be found.

The distributions of the 28 morphospecies show strong geographic structure within the upper Río Pastaza watershed. The morphospecies found north of the Río Pastaza are not found south of it, and viceversa, with one possible exception. These patterns are probably not sampling artifacts, as we have intensively examined each of the mountains where these longrepent Teagueia are known to occur. Such strong local distribution patterns are remarkable in light of the dispersal characteristics of orchid seeds. Other orchid genera in the same area show north-south distribution bands which cross the Río Pastaza (LJ pers. obs.)

The previously-described members of this group of 28 morphospecies, T. alyssana, T. sancheziae, $T$. cymbisepala, and $T$. jostii, were all from a mountain north of the Río Pastaza. The two species described in the present paper are the first species described from south of the Río Pastaza. They are among the most distinctive of the southern species.

Habitat and conservation status. Both species described here were discovered at very high elevations on Cerro Candelaria, Tungurahua province, Ecuador. Fourteen other morphospecies of Teagueia were also found on Cerro Candelaria. The two species described here are among the rarest of the Cerro Candelaria Teagueia species; only a few plants of each were found during extensive fieldwork on Cerro Candelaria. Teagueia puroana grows as an epiphyte on low branches and trunks of isolated stunted treelets in the páramo. Teagueia barbeliana grows in moss in open páramo at $3400-3800 \mathrm{~m}$. Both species experience hard freezes on most nights.

Teagueia barbeliana was later found on a second mountaintop about $18 \mathrm{~km}$ west of Cerro Candelaria. Teagueia puroana remains known only from Cerro Candelaria. The extraordinary scientific importance of this unique evolutionary radiation makes these mountains a global conservation priority. Shortly after their discovery, the first author and his associates in Ecuador and abroad started a conservation foundation, Fundación EcoMinga, to protect the endemic plants and animals of the upper Río Pastaza watershed. In partnership with the World Land Trust, Fundación EcoMinga has now purchased much of 
Cerro Candelaria, including habitat for T. puroana and T. barbeliana and the fourteen other Teagueia morphospecies which grow there. These purchases were made possible by donations to the World Land Trust by Puro Coffee, Albertino Abela, and PricewaterhouseCoopers.

\section{SPECIES DESCRIPTIONS}

Teagueia barbeliana L. Jost \& A. Shepard, sp. nov.

Teagueiae cymbisepalae Luer et Jost similis, sed sepalis petalisque rotundioribus, sepalis lateralibus connatis per 1/2 marginem suas, lobis lateralibus labelli circum columnam.

TYPE: Ecuador. Tungurahua: Cerro Candelaria, $1^{\circ} 28^{\prime} 46^{\prime \prime}$ S, 78 ${ }^{\circ} 17^{\prime} 51^{\prime \prime} \mathrm{W}, 3400$ m, Nov. 2002, L. Jost 5132 (holotype: QCA!; isotype: QCNE!). Fig. 1.

Plant medium in size for the genus, lithophytic or terrestrial, long-repent, the rhizome exceeding 20 $\mathrm{cm}$ in length, producing a ramicaul and leaf at every third joint, 7-8 $\mathrm{mm}$ between joints; one coarse root emerging at each ramicaul-bearing joint. Ramicauls ascending, stout, $3 \mathrm{~mm}$ long, enclosed by 1 or 2 imbricating sheaths. Leaf erect, thickly coriaceous, reticulate-veined, petiolate, elliptical, obtuse, 10-15 $\mathrm{mm}$ long, 8-9 $\mathrm{mm}$ wide, the base cuneate into the petiole. which is $15-20 \mathrm{~mm}$ long. Inflorescence from near the apex of the ramicaul; an erect, successive, distantly several-flowered raceme, $4-6 \mathrm{~cm}$ to first flower, flowers spaced $12 \mathrm{~mm}$ apart, up to 7 flowers; one to three flowers open at once; floral bracts oblique, acute, thin, $4 \mathrm{~mm}$ long; pedicels $4.4 \mathrm{~mm}$ long; ovary $1.8 \mathrm{~mm}$ long. Flowers golden yellow suffused orange, with red on veins, the lip with a red stripe down its center; dorsal sepal ovate, $6.4 \mathrm{~mm}$ long, $4.2 \mathrm{~mm}$ wide, 3 -veined; lateral sepals broadly ovate, acuminate, 5.3 $\mathrm{mm}$ long, $3.9 \mathrm{~mm}$ wide, 3 -veined, rudimentary fourth vein, connate for $2.3 \mathrm{~mm}$. Petals ovate, acuminate, $4.1 \mathrm{~mm}$ long, $2.8 \mathrm{~mm}$ wide, 3-veined. Lip ovate, 3.1 $\mathrm{mm}$ long, $2.3 \mathrm{~mm}$ wide, the apex truncate, the disc longitudinally cleft, spreading into a deep orifice above the middle, the base with angles embracing the column, curving outward to match the plane of the midlobe of the lip, the base fixed to the column-foot. Column terete, recurved at anther, $1.8 \mathrm{~mm}$ long, 1 $\mathrm{mm}$ wide at stigma, laterally winged at anther, wings confluent with stigma, stigma entire.

Eтymology: Albertino Abela of London contributed significantly to the conservation of this orchid's habitat; this species is named in honor of his mother Barbel, at his request.

PARATYPES: Ecuador. Tungurahua: Cerro Candelaria, 1²8'46”S, 78¹7'51'W, Nov. 2003, L. Jost, A. Shepard, S. Grossman, A. Araujo 6197 (QCA!), 6219 (QCA!), 6225 (QCA!), 6227 (QCA!); Cerro Chamana, 1²6'7'S, 78²3'1'W, 3500 m, Dec. 2003, L. Jost et al. 6580 (QCA!).

Distribution: Rare and local from 3400-3800 m on two mountaintops just south of the Río Pastaza near the town of Baños, Tungurahua, Ecuador.

\section{Teagueia puroana L. Jost \& A. Shepard, sp. nov.}

Teagueiae alyssanae Luer et Jost similis, sed sepalis petalisque longi-acuminatis, sepalis lateralibus connatis per 1/5 marginem suas, lobis lateralibus labelli circum columnam.

Type: Ecuador. Tungurahua: Cerro Candelaria, 1²8'46”'S, 78¹7'51'W, 3400 m, Nov. 2002, L. Jost 5149 (holotype: QCA!). Fig. 2.

Plant small-medium in size for the genus, epiphytic, long-repent, the rhizome exceeding $13 \mathrm{~cm}$ long, producing a ramicaul and leaf at every third joint, 0.8 $1.4 \mathrm{~cm}$ between joints; one coarse root emerging at each ramicaul-bearing joint. Ramicauls ascending, stout, $4 \mathrm{~mm}$ long, enclosed by 1 or 2 imbricating sheaths. Leaf erect, thickly coriaceous, reticulate-veined, petiolate, elliptical, obtuse, 15-20 mm long, 8-9 mm wide, the base cuneate into the petiole $15 \mathrm{~mm}$ long. Inflorescence from near the apex of the ramicaul; an erect, successive, distantly several-flowered raceme, 2-4.5 $\mathrm{cm}$ to first flower, the flowers spaced 5-7 mm apart, up to 11 flowers, with only one or two flowers open at once; floral bracts oblique, acute, thin, $4 \mathrm{~mm}$ long; pedicels 3.8-4.5 mm long; ovary $1.5 \mathrm{~mm}$ long. Flowers dark orange suffused dark reddish apically on all parts; dorsal sepal elliptical-ovate, longacuminate, $7.1 \mathrm{~mm}$ long, $3.4 \mathrm{~mm}$ wide, 3-veined; lateral sepals obovate, long-acuminate, $7.6 \mathrm{~mm}$ long, $2.6 \mathrm{~mm}$ wide, 3-veined, connate for $1.4 \mathrm{~mm}$; 

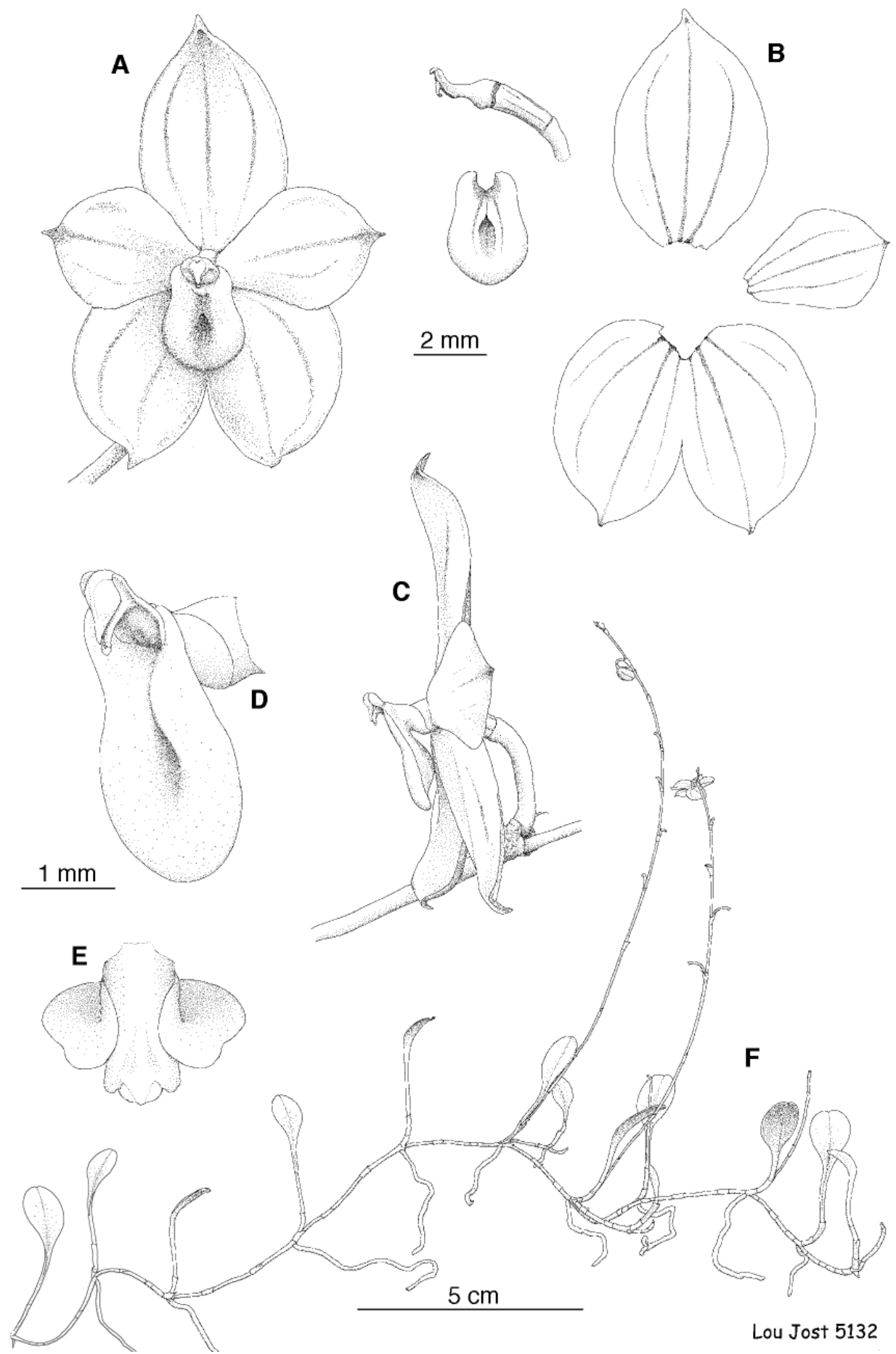

\section{$\mathrm{mm}$}

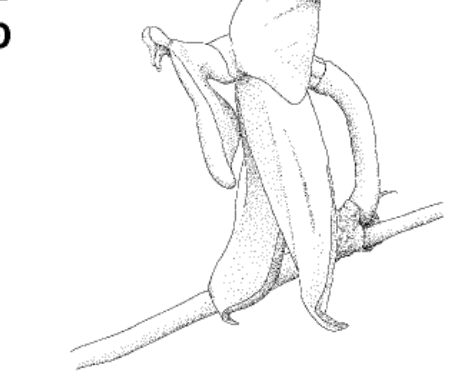

c 


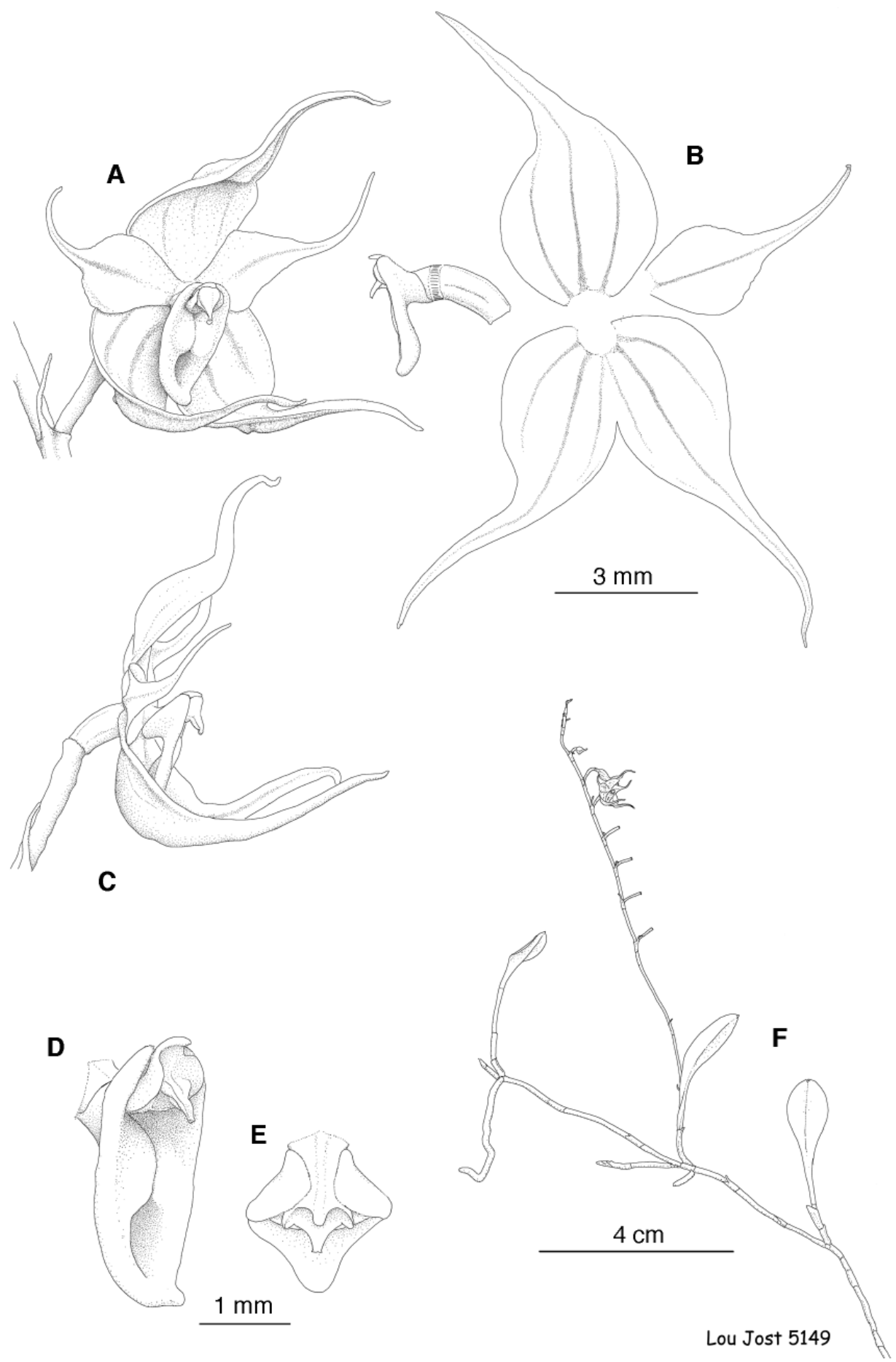

FigURE 2. Teagueia puroana L.Jost \& A.Shepard. A - Plant. B - Flower. C - Lateral flower. D - Dissected flower. E — Oblique lip and column detail. F - Top view, column and lip collar. Scale bars: A, $4 \mathrm{~cm}$; B-D, $3 \mathrm{~mm}$; E-F, $1 \mathrm{~mm}$. ILLUSTRATION VOUCHER: L. Jost 5149 (QCA). Illustration by Lou Jost. 
petals ovate, long-acuminate, $5.1 \mathrm{~mm}$ long, $2 \mathrm{~mm}$ wide, 1-veined; lip oblong-ovate, $2.4 \mathrm{~mm}$ long, 1.4 $\mathrm{mm}$ wide, the apex rounded, the disc longitudinally cleft, spreading into a deep orifice above the middle, the base with rounded microscopically ciliate angles embracing the column, the angles nearly or actually in contact with each other above the column, the base fixed to the column-foot. Column terete, recurved at anther, $1.4 \mathrm{~mm}$ long, $0.8 \mathrm{~mm}$ wide at stigma; stigma entire.

Etymology: Named in honor of Puro Coffee, UK, which contributed significantly to the conservation of this species.

Paratypes: Ecuador. Tungurahua: Cerro Candelaria, 3600 m, $1^{\circ} 28^{\prime} 46$ "'S, $78^{\circ} 17^{\prime} 51^{\prime \prime} \mathrm{W}$, Nov. 2002, L. Jost 5140 (QCA!), 5141 (QCA!), 5209 (QCA!), 5210 (QCA!), L. Jost, A. Shepard, S. Grossman, A. Araujo 6213 (QCNE!), 6218 (QCA!), 6223 (QCA!).

Distribution: Known only from $3600 \mathrm{~m}$ on Cerro Candelaria, just south of the Río Pastaza, near the town of Baños, Tungurahua, Ecuador.

AcKnowledgements. Kurt Neubig, Lorena Endara, Mark Whitten, and two anonymous reviewers gave advice that improved the manuscript. The Ministerio del Ambiente del Ecuador gave permission for this research; permit 12-07 ICFLO- DNBAPVS/MA and previous permits.

\section{LiterATURE CITED}

Barkman, T.J., \& B.B. Simpson. 2001. Origin of HighElevation Dendrochilum Species (Orchidaceae) Endemic to Mount Kinabalu, Sabah, Malaysia. Syst. Bot. 26: 658-669.

Hughes, C., \& Eastwood, R. 2006. Island Radiation on a continental scale: Exceptional rates of plant diversification after uplift of the Andes. PNAS, 103:10334-10339.

Jost, L. 2004. Explosive Local Radiation of the Genus Teagueia (Orchidaceae) in the Upper Pastaza Watershed of Ecuador. Lyonia 7: 41-47.

Luer, C.A. 1991. Icones Pleurothallidinarum VIII, Systematics of Lepanthopsis, Restrepiella, Restrepiopsis, Salpistele \& Teagueia. Monogr. Syst. Bot. Missouri Bot. Gard. 64: 105-114.

Luer, C.A. 2000. Icones Pleurothallidinarum XX. Systematics of Jostia, Andinia, Barbosella,

Barbodria, and Pleurothallis Subgenus Antilla, Subgenus Effusia, Subgenus Restrepioidia

(Orchidaceae). Monogr. Syst. Bot. Missouri Bot. Gard. 79:105-114.

Scherson, R., Vidal, R., \& Sanderson, M. 2008. Phylogeny, biogeography, and rates of diversification of New World Astragalus (Leguminosae) with an emphasis on South American radiations. Am. J. Bot. 95: 1030-1039.

Tye, A. 2000. Las plantas vasculares endemicas de Galapagos. Pages 24-28 in Valencia, R., Pitman, N., Leon-Yanez, S., Jorgensen, P. (Eds.) Libro Rojo de las Plantas endemicas del Ecuador 2000. Herbarium of the Pontificia Universidad Catolica del Ecuador. Quito. 